\title{
Effect of inoculation method and plant growth medium on endophytic colonization of sorghum by the entomopathogenic fungus Beauveria bassiana
}

\author{
Tadele Tefera $\cdot$ Stefan Vidal
}

Received: 11 December 2008/ Accepted: 11 March 2009/Published online: 24 March 2009

(C) The Author(s) 2009. This article is published with open access at Springerlink.com

\begin{abstract}
A study was conducted to determine the effect of inoculation method and plant growth medium on colonization of sorghum by an endophytic Beauveria bassiana. Colonization of leaves, stems, and roots by $B$. bassiana was assessed 20-days after application of the fungus. Although $B$. bassiana established as an endophyte in sorghum leaves, stems, and roots regardless of inoculation method (leaf, seed, or soil inoculation), plant growth medium (sterile soil, non-sterile soil, or vermiculite) apparently influenced colonization rates. Seed inoculation with conidia caused no stem or leaf colonization by the fungus in non-sterile soil but did result in substantial endophytic colonization in vermiculite and sterile soil. Leaf inoculation did not result in root colonization, regardless of plant growth medium. Endophytic colonization was greater in leaves and stems than roots. Endophytic colonization by B. bassiana had no adverse effects on the growth of sorghum plants. Leaf inoculation with a conidial suspension proved to be the best method to introduce $B$. bassiana into sorghum leaves for plants growing in either sterile or nonsterile soil. Further research should focus on the
\end{abstract}

Handling Editor: Helen Roy.

T. Tefera $\cdot$ S. Vidal $(\bowtie)$

Department of Crop Science, Agricultural Entomology

Division, Georg-August University Goettingen,

Grisebachstrasse 6, 37077 Goettingen, Germany

e-mail: svidal@gwdg.de virulence of endophytic $B$. bassiana against sorghum stem borers.

Keywords Beauveria bassiana - Endophyte · Inoculation method P Plant growth medium . Sorghum

\section{Introduction}

Lepidopteran stem borers, specifically Chilo partellus Swinhoe (Crambidae), Busseola fusca Fuller (Noctuidae), and Sesamia calamistis Hampson (Noctuidae), are the most important pests of maize and sorghum in Africa and Asia (Bosque-Perez and Schulthess 1998). Females lay eggs on the underside of leaves, and first instar larvae feed on leaf whorls on young leaves. Second instar larvae penetrate the stem tissues to feed internally, producing extensive tunnels in stems. After excavating emergence windows to facilitate the exit of moths, the second instar larvae pupate in the tunnels. Control of these pests has been based on application of chemical insecticides (Warui and Kuria 1983; van Rensburg and van den Berg 1992) but insecticides have limited effectiveness because of the cryptic feeding of these pests.

Fungal endophytes play an important role in protecting plants against herbivorous insects (Jallow et al. 2004, 2008) and plant pathogens (Ownley et al. 2008). Beauveria bassiana has been reported as an 
endophyte in a variety of plants, including maize (Bing and Lewis 1991, 1992a, b; Wagner and Lewis 2000), Theobroma gileri (Evans et al. 2003), Carpinus caroliniana (Bills and Polishook 1991), in seeds and needles of Pinus monticola (Ganley and Newcombe 2005) in opium poppies (Quesada-Moraga et al. 2006), in banana tissue cultures (Akello et al. 2007), and in coffee (Posada et al. 2007). Bing and Lewis (1991) demonstrated that B. bassiana is able to invade maize plants via the epidermis, thereafter persisting in the plant though the entire growing season and reducing tunneling by Ostrinia nubilalis (Lepidoptera: Pyralidae).

No reports are yet available on the potential of B. bassiana to establish as an endophyte in sorghum, an important cereal crop in Africa. The use of B. bassiana as an artificial endophyte (i.e., one that is inoculated onto the plant rather than naturally infecting the plant) in sorghum could reduce the damage caused by the larvae of stem borers. For the endophytic $B$. bassiana to be used in practical agronomic production, reliable and practical methods of inoculum delivery must be developed. Preliminary studies showed that B. bassiana colonizes sorghum (Tefera and Vidal, unpublished), but the rate of colonization may depend on how the plant is exposed to the fungus. Therefore, the present work evaluated the effects of inoculation method and plant growth medium on endophytic colonization of sorghum by B. bassiana as part of a biological control system of sorghum stem borers.

\section{Materials and methods}

Fungus

The experiments used strain Bb-04 of B. bassiana, which had been isolated from the maize stem borer B. fusca at the Haramaya University, Ethiopia. This fungal strain was selected based on its virulence to the spotted stem borer $C$. partellus in previous studies (Tefera and Pringle 2004). Fungus cultures were maintained at $25^{\circ} \mathrm{C}$ on Sabouraud dextrose agar (SDA), containing $10 \mathrm{~g}$ enzymatic digest casein, $40 \mathrm{~g}$ dextrose, and $15 \mathrm{~g}$ agar. Conidia were obtained from 3-week-old sporulating cultures. The conidia were harvested by scraping the surface of the culture with a sterile camel hairbrush into a 500-ml glass beaker containing $50 \mathrm{ml}$ sterile distilled water plus Tween $80\left(0.1 \% \mathrm{v} / \mathrm{v} ;\right.$ Difco $\left.^{\mathrm{TM}}\right)$. The conidial suspension was prepared by mixing the solution with a magnetic stirrer for $5 \mathrm{~min}$. The conidia concentration was then adjusted to the desired concentration of $1 \times 10^{8}$ conidia $\mathrm{ml}^{-1}$ with a Thoma Chamber using a light microscope $(40 \times$ magnifications) following the procedures described by Goettel and Inglis (1997). To assess viability of the conidia, germination test was carried out on SDA after incubation for $24 \mathrm{~h}$ at $23^{\circ} \mathrm{C}$. The germination exceeded $90 \%$. A suspension of $1 \times 10^{8}$ conidia $\mathrm{ml}^{-1}$ was used in the experiments.

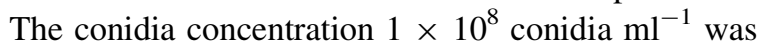
chosen based on virulence of the isolate to $C$. partellus at this concentration (Tefera and Pringle 2004).

Sorghum plants

The experiments used the sorghum cultivar P9403, commonly called "Abshir", from the Haramaya University, Ethiopia, released by Purdue University (USA) to east Africa due to its resistance to witchweed (striga sp.), a parasitic plant. Although it is widely grown in different agronomic regions of Ethiopia, where the grain is used for human consumption and the crop residue is used for animal feed, P9403 is susceptible to stem borers. As described in the following paragraphs, the sorghum was inoculated with $B$. bassiana in one of three ways (by inoculating seeds, leaves, or soil), and the inoculated plants were grown in one of three media (vermiculite, sterile soil, or non-sterile soil).

Experiment-I: effect of inoculation method on colonization of sorghum by $B$. bassiana

Seeds were surface sterilized by submerging them in $3 \%$ sodium hypochlorite for $3 \mathrm{~min}$ and then in $75 \%$ ethanol for $2 \mathrm{~min}$; the seeds were then rinsed in sterile water three times. The treated seeds were placed on sterile filter papers to dry for $30 \mathrm{~min}$ before being divided into two portions. The first portion was used for seed inoculation while the second portion was used for leaf and soil drench inoculations after seedling emergence. The seeds intended for leaf and soil inoculation were planted in pots filled with approximately $2 \mathrm{~kg}$ of sterile potting soil (autoclaved 
at $121^{\circ} \mathrm{C}$ for $15 \mathrm{~min}$ ), non-sterile potting soil, or vermiculite. The plants were maintained in the greenhouse at $21-22^{\circ} \mathrm{C}, 60-80 \% \mathrm{RH}$, and with a 12-h photoperiod. Four seeds were planted per pot and were thinned to two seedlings after emergence.

For seed inoculation, $50 \mathrm{~g}$ seeds were immersed into $10 \mathrm{ml} \mathrm{B}$. bassiana conidial suspension $\left(1 \times 10^{8}\right.$ conidia $\mathrm{ml}^{-1}$ ) for $10 \mathrm{~min}$. After the inoculated seeds were dried on sterile tissue paper for $30 \mathrm{~min}$, they were planted in pots as described in the previous paragraph. However, the exact rate of conidia that was attached to the seeds was not determined. Control seeds were immersed in sterile distilled water. For leaf inoculation, a plastic hand sprayer (500-ml capacity) was used to inoculate each seedling with a 3 -ml conidial suspension $\left(1 \times 10^{8}\right.$ conidia $\mathrm{ml}^{-1}$ ) seven days after emergence. The spray was directed to the leaves but might have incidentally drifted to the stems. To avoid conidial runoff to the soil, the top of each pot was covered with aluminum foil (Posada et al. 2007). The control plants were inoculated with sterile distilled water. For soil inoculation, a 3 -ml conidial suspension $\left(1 \times 10^{8}\right.$ conidia $\mathrm{ml}^{-1}$ ) was applied around the root zone of each seedling. The control plants were inoculated with 3-ml sterile distilled water. Seedlings in all treatments were watered as needed. To avoid conidial runoff from the treated leaves to the stem and soil, watering device was carefully directed to the surface of the pot.

Separate experiments were conducted using nonsterile soil, sterile soil, and vermiculite. Within each experiment, a completely randomized block design with ten replicates per treatment (inoculation method) was used.

Experiment-II: effect of plant growth medium on colonization of sorghum by $B$. bassiana

We conducted an experiment to determine the effect of the three plant growth media (vermiculite, sterile soil, or non-sterile soil), on colonization of sorghum by B. bassiana, using the seed inoculation method. Nontreated seeds were included as a control for each plant growth medium. A complete randomized block design with ten replicates was used. We followed the same treatment application procedures and experimental management as described above in experiment-I for the seed inoculation.

\section{Data collection and statistical analysis}

\section{Colonization}

Colonization of sorghum seedlings by $B$. bassiana was determined 20 days after inoculation with $B$. bassiana. Seedlings were carefully removed from pots, and roots were gently washed with tap water. The seedlings were then separated into leaves, stems, and roots. These parts were surface-sterilized with $1 \%$ sodium hypochlorite for $3 \mathrm{~min}$, rinsed twice in sterile distilled water, and then placed on sterile tissue paper in a laminar flow cabinet. Five leaf, stem and root pieces of approximately $2-\mathrm{mm}^{2}$ from each seedling were randomly taken and placed separately on B. bassiana selective medium (2\% oatmeal infusion, $2 \%$ agar, $550 \mu \mathrm{g} \mathrm{ml}^{-1}$ dodine, $5 \mu \mathrm{g} \mathrm{ml}^{-1}$ crystal violet) (Chase et al. 1986). To evaluate the efficacy of the surface sterilization method $20 \mathrm{ml}$ of the water used to rinse the tissues after surface sterilization was taken and $20 \mu \mathrm{l}$ aliquots of a $10^{-3}$ dilution were plated on the selective media and spread with a sterile glass rod, incubated for ten day at $22 \pm 2{ }^{\circ} \mathrm{C}$ to count for colony forming units. However, the sterilization resulted in no growth of microorganisms; thus any ensuing $B$. bassiana growth from surface-sterilized tissues is inferred to have originated from internal plant tissues as endophytes. The presence or absence of $B$. bassiana growth on the pieces was recorded after ten days at $20-23^{\circ} \mathrm{C}$. A total of 120 plants and 600 plant pieces were examined in experiment-I, while a total of 60 plants and 180 plant pieces were examined in experiment-II. The data were expressed as colonization frequencies: colonization frequency $=$ $100 \times$ (number of plant pieces colonized/total number of plant pieces) (Petrini and Fisher 1987). The colonization frequency data (expressed as percentages) were angular transformed to stabilize the variances. The transformed data were analyzed using analysis of variances (ANOVA) of the program SPSS Version 16. Significant differences between means were determined with the Student-Newman-Keuls test $(P=0.05)$.

\section{Plant growth}

The effect of the fungus on plant growth (Experiment-I) was determined by measuring shoot height, root length, and shoot and root fresh weight 35 days 
after inoculation of the plants with the fungus. Plant height was measured from the soil surface to the tip of the stem. After shoot fresh weight, root fresh weight (roots had been washed to remove soil), and root length were recorded, the fresh shoots and roots were placed in a paper bag and kept at $45^{\circ} \mathrm{C}$ for six days before dry weights were determined. The plant growth data were subjected to one-way ANOVA using the SPSS Version 16. Significant differences between means were determined with the Student-Newman-Keuls test $(P=0.05)$.

\section{Results}

Experiment-I: effect of inoculation method on colonization by B. bassiana and the growth of sorghum

No B. bassiana was recorded from the control plants growing in non-sterile soil, sterile soil, or vermiculite (data not shown). For sorghum growing in non-sterile soil, inoculation method significantly affected the colonization of leaves $\left(P<0.01 ; F_{2,27}=73.61\right)$ and stems $\left(P<0.01 ; F_{2,27}=22.53\right)$ but not roots $(P=$ $0.35 ; F_{2,27}=1.08$ ) by $B$. bassiana (Fig. 1a). Leaf and stem colonization were highest with leaf inoculation, lower with soil inoculation, and nondetectable with seed inoculation. Root colonization was much lower than leaf and stem colonization. Although the differences were not significant, root colonization was highest with seed inoculation, lower with soil inoculation, and non-detectable with leaf inoculation.

For sorghum growing in sterile soil, inoculation method significantly affected the colonization of leaves $\left(P<0.01 ; F_{2,27}=40.68\right)$, stems $(P<0.01$; $\left.F_{2,27}=50.62\right)$, and roots $\left(P=0.35 ; F_{2,27}=15.77\right)$ by $B$. bassiana (Fig. 1b). Leaf inoculation resulted in the highest leaf colonization, while seed inoculation caused the highest stem and root colonization. Regardless of plant part colonized, colonization by B. bassiana of sorghum growing in sterile soil was low with soil inoculation.

For sorghum growing in vermiculite, inoculation method significantly affected colonization of roots $\left(P<0.01 ; F_{2,27}=692.1\right)$ but not of leaves and stems by $B$. bassiana (Fig. 1c). Colonization was greater than $90 \%$ with all inoculation methods and plant parts
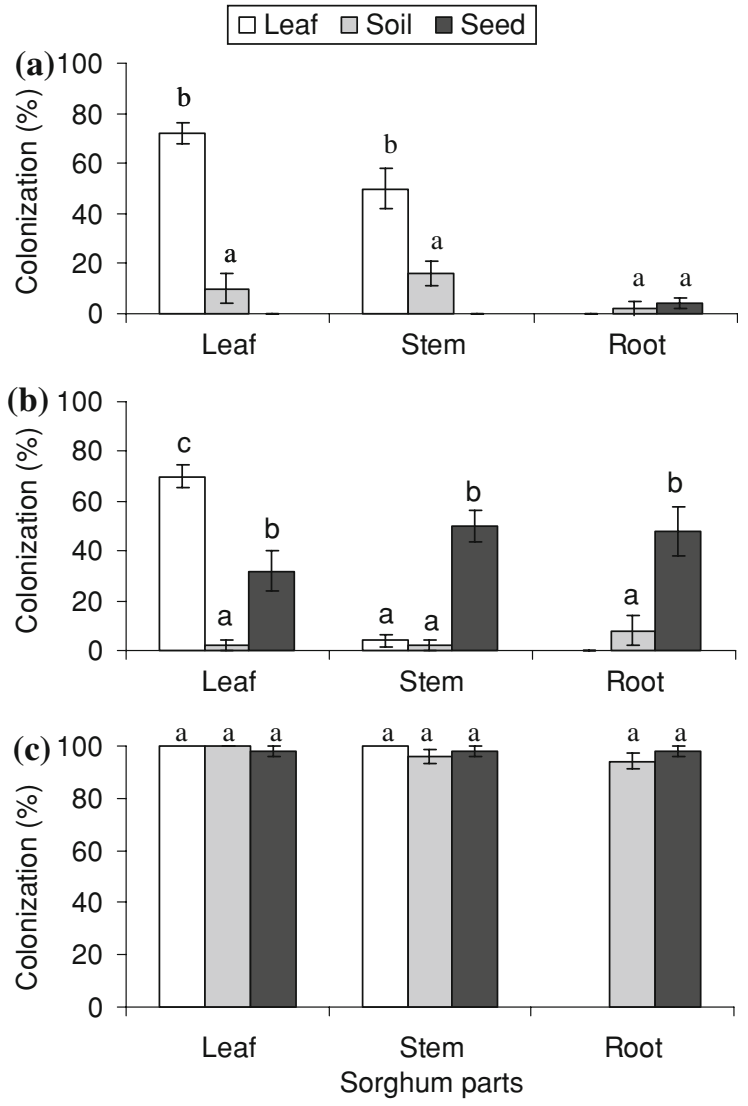

Fig. 1 Mean $( \pm \mathrm{SE})$ percent colonization of sorghum leaves, stems, and roots by Beauveria bassiana as affected by inoculation method (leaf, seed, or soil inoculation) of plants grown in (a) non-sterile soil, (b) sterile soil and (c) vermiculite

except that colonization was $0 \%$ with leaf inoculation of roots.

Within each experiment (i.e., for each growth medium), plant height, fresh weight, and dry weight were not significantly affected by inoculation method (Table 1), i.e., inoculation of sorghum with B. bassiana did not reduce plant growth. Although statistical analysis could not be used to compare plant growth in different growth media, plant growth appeared to differ with growth media. Plants grown in vermiculite were much shorter and weighed less than plants grown in sterile or non-sterile soil.

Experiment-II: effect of plant growth medium on colonization of sorghum by $B$. bassiana

We found significant differences with regard to the growth medium affecting leaf $(P<0.01$; 
Table 1 Height and weight of sorghum plants treated with B. bassiana as affected by inoculation method and plant growth medium (vermiculite, non-sterile soil, or sterile soil, respectively)

\begin{tabular}{|c|c|c|c|c|c|c|}
\hline $\begin{array}{l}\text { Inoculation } \\
\text { method }\end{array}$ & $\begin{array}{l}\text { Shoot } \\
\text { height }(\mathrm{cm})\end{array}$ & $\begin{array}{l}\text { Root } \\
\text { length (cm) }\end{array}$ & $\begin{array}{l}\text { Fresh shoot } \\
\text { weight }(\mathrm{g})\end{array}$ & $\begin{array}{l}\text { Fresh root } \\
\text { weight }(\mathrm{g})\end{array}$ & $\begin{array}{l}\text { Dry shoot } \\
\text { weight }(\mathrm{g})\end{array}$ & $\begin{array}{l}\text { Dry root } \\
\text { weight }(\mathrm{g})\end{array}$ \\
\hline \multicolumn{7}{|l|}{ Vermiculite } \\
\hline Seed & $22.0 \pm 0.7 \mathrm{a}$ & $20.6 \pm 0.6 \mathrm{a}$ & $0.42 \pm 0.01 \mathrm{a}$ & $0.86 \pm 0.02 \mathrm{a}$ & $0.12 \pm 0.01 \mathrm{a}$ & $0.14 \pm 0.01 \mathrm{a}$ \\
\hline Leaf & $22.1 \pm 0.7 \mathrm{a}$ & $22.4 \pm 0.4 a$ & $0.46 \pm 0.05 a$ & $0.85 \pm 0.02 \mathrm{a}$ & $0.12 \pm 0.02 \mathrm{a}$ & $0.15 \pm 0.01 \mathrm{a}$ \\
\hline Soil & $22.1 \pm 0.7 \mathrm{a}$ & $22.0 \pm 0.8 \mathrm{a}$ & $0.40 \pm 0.09 a$ & $0.86 \pm 0.02 \mathrm{a}$ & $0.11 \pm 0.02 \mathrm{a}$ & $0.17 \pm 0.06 a$ \\
\hline Control & $21.4 \pm 0.3 \mathrm{a}$ & $21.4 \pm 0.6 \mathrm{a}$ & $0.39 \pm 0.07 \mathrm{a}$ & $0.84 \pm 0.03 a$ & $0.11 \pm 0.01 \mathrm{a}$ & $0.13 \pm 0.03 a$ \\
\hline \multicolumn{7}{|l|}{ Sterile soil } \\
\hline Seed & $70.7 \pm 0.6 \mathrm{a}$ & $23.3 \pm 0.8 \mathrm{a}$ & $7.1 \pm 0.2 \mathrm{a}$ & $2.6 \pm 0.4 \mathrm{a}$ & $1.2 \pm 0.02 \mathrm{a}$ & $0.31 \pm 0.04 \mathrm{a}$ \\
\hline Leaf & $69.3 \pm 0.4 a$ & $21.6 \pm 0.4 a$ & $6.8 \pm 0.1 \mathrm{a}$ & $2.8 \pm 0.1 \mathrm{a}$ & $1.2 \pm 0.02 \mathrm{a}$ & $0.34 \pm 0.03 \mathrm{a}$ \\
\hline Soil & $70.9 \pm 0.7 \mathrm{a}$ & $21.6 \pm 0.7 \mathrm{a}$ & $7.5 \pm 0.1 \mathrm{a}$ & $2.6 \pm 0.4 \mathrm{a}$ & $1.2 \pm 0.02 \mathrm{a}$ & $0.39 \pm 0.03 a$ \\
\hline Control & $70.1 \pm 0.5 a$ & $21.5 \pm 0.5 a$ & $7.6 \pm 0.1 \mathrm{a}$ & $2.7 \pm 0.1 \mathrm{a}$ & $1.1 \pm 0.02 \mathrm{a}$ & $0.46 \pm 0.02 \mathrm{a}$ \\
\hline \multicolumn{7}{|c|}{ Non-sterile soil } \\
\hline Seed & $60.8 \pm 0.8 \mathrm{a}$ & $31 \pm 1.7 \mathrm{a}$ & $6.6 \pm 0.2 \mathrm{a}$ & $2.5 \pm 0.05 a$ & $0.58 \pm 0.03 \mathrm{a}$ & $0.13 \pm 0.01 \mathrm{a}$ \\
\hline Leaf & $62.1 \pm 1.6 a$ & $31.8 \pm 19 a$ & $7.2 \pm 0.3 \mathrm{a}$ & $2.5 \pm 0.08 \mathrm{a}$ & $0.49 \pm 0.03 \mathrm{a}$ & $0.14 \pm 0.04 a$ \\
\hline Soil & $58.7 \pm 1.5 \mathrm{a}$ & $34.9 \pm 1.7 \mathrm{a}$ & $6.7 \pm 0.3 a$ & $2.4 \pm 0.07 \mathrm{a}$ & $0.50 \pm 0.04 \mathrm{a}$ & $0.15 \pm 0.01 \mathrm{a}$ \\
\hline Control & $62.2 \pm 1.1 \mathrm{a}$ & $31.7 \pm 1.7 \mathrm{a}$ & $6.5 \pm 0.2 \mathrm{a}$ & $2.6 \pm 0.05 a$ & $0.51 \pm 0.05 \mathrm{a}$ & $0.17 \pm 0.01 \mathrm{a}$ \\
\hline
\end{tabular}

For each growth medium, means $( \pm \mathrm{SE})$ followed by the same letter within a column are not significantly different at $P<0.05$

$\left.F_{2,27}=134.9\right)$, stem $\left(P<0.01 ; F_{2,27}=469.4\right)$ and root $\left(P<0.01 ; F_{2,27}=228.9\right)$ colonization of sorghum by B. bassiana (Table 2), respectively. Growing $B$. bassiana treated seeds in non-sterile soil did not result in leaf and stem colonization, and root colonization by the fungus was limited. However, when sorghum seeds were grown in sterile soil and vermiculite, fungal colonization was observed in leaf, stem and root parts. Colonization was higher for seeds grown in vermiculite as compared to sterile soil. No B. bassiana was recorded from the control plants.

\section{Discussion}

This study demonstrates that B. bassiana can be established as an endophyte in sorghum leaves, stems,

Table 2 Effect of plant growth medium on sorghum leaf, stem and root colonization by $B$. bassiana

\begin{tabular}{lccc}
\hline Growth medium & \multicolumn{4}{l}{ Plant parts colonized $(\%)$} \\
\cline { 2 - 4 } & Leaf & Stem & \multicolumn{1}{l}{ Root } \\
\hline Non-sterile soil & $0 \pm 0 \mathrm{a}$ & $0 \pm 0 \mathrm{a}$ & $16 \pm 2.7 \mathrm{a}$ \\
Sterile soil & $32 \pm 5.3 \mathrm{~b}$ & $40 \pm 5.9 \mathrm{~b}$ & $48 \pm 3.2 \mathrm{~b}$ \\
Vermiculite & $92 \pm 5.3 \mathrm{c}$ & $100 \pm 0 \mathrm{c}$ & $100 \pm 0 \mathrm{c}$ \\
\hline
\end{tabular}

Means ( \pm SE) followed by the same letter within a column are not significantly different at $P<0.05$ and roots, by inoculating leaves, seeds, or soil. However, the level of colonization seemed to be substantially affected by plant growth medium. Although the effect of growth medium on plant colonization by the fungus has not been previously considered, successful colonization of many plant species following inoculation with $B$. bassiana has been reported previously (Jones 1994, Bing and Lewis 1991, 1992a, b; Wagner and Lewis 2000; Ownley et al. 2008; Quesada-Moraga et al. 2006; Posada and Vega 2005; 2006; Posada et al. 2007; Akello et al. 2007). Endophytic colonization by B. bassiana however, depended upon the inoculation method, fungal isolate, and plant species. For example, the highest post-inoculation recovery of $B$. bassiana occurred after direct injection in coffee (Posada et al. 2007), dipping plants in conidial suspension in banana tissue culture (Akello et al. 2007), foliar application in opium poppy (Quesada-Moraga et al. 2006) and maize (Bing and Lewis 1991, 1992a, b), and seed coating in tomato (Ownley et al. 2008).

In the current study, B. bassiana colonization differed among the plant parts. Leaves and stems were colonized to a greater extent than roots. The colonization of the different plant parts indicate that the fungus moves within the plant system. The reason for higher colonization of leaves and stems is not 
clear but could reflect differences in microbial and physiological conditions in the different plant parts. Petrini and Fisher (1987) and Liang-Dong et al. (2008) reported that endophytic fungi exhibited tissue specificity because they are adapted to particular conditions present in a given plant part.

Planting conidia-treated seeds in vermiculite and sterile soil, rather than in non-sterile soil, improved endophytic colonization of $B$. bassiana. Autoclaving the soil might have eliminated microorganisms that otherwise would have competed with or antagonized B. bassiana. However, seed and soil inoculation methods did not significantly increase in endophytic colonization by the fungus in non-sterile soils, compared to leaf inoculation method. The reason for the lack of endophytic colonization in seeds treated with $B$. bassiana in non-sterile soil is not clear and requires further investigation. Abiotic and biotic soil factors, however, were reported to affect occurrence of the entomopathogenic fungus Beauveria brongniartii after application at different times of the year (Kessler et al. 2003). The low endophytic colonization of the fungus in non-sterile soil suggests that biotic factors may have a stronger influence on the fungus than abiotic factors. Fungistatic effects of soil (Lingg and Donaldson 1981) and soil antagonism (Pereira et al. 1993) have been reported for B. bassiana. In the non-sterile soil, biotic antagonism may have inhibited germination of $B$. bassiana conidia or prevented the fungus from penetrating roots. For instance, the common soil fungus Penicillium urticae produces a water soluble inhibitor of B. bassiana (Shields et al. 1981). Another common soil saprophyte, Aspergillus clavatus, also produces metabolites that are fungicidal to $B$. bassiana (Majchrowicz et al. 1990). Vänninen et al. (2000) and Pereira et al. (1993) reported that B. bassiana had a low persistence in soils and that the fungus infected only a small proportion of insects when conidia were added directly to the soil.

Plant growth was affected by the growth medium (sterile soil, non-sterile soil, and vermiculite) but not by the inoculation method. Plant growth in vermiculite was much less than in sterile and non-sterile soil, regardless of the inoculation method. Lewis et al. (2001) reported no differences in growth between plants treated or not treated with $B$. bassiana. In the current study, seed treatment with $B$. bassiana did not reduce seed germination or seedling growth, and did not result in the development of root disease. Application of $B$. bassiana to leaves, seeds, or soil did not result in significant differences in plant height, fresh weight, or dry weight. Although differences in plant growth and dry weight were evident when plants were grown in vermiculite, sterile soil, and non-sterile soil, these differences apparently did not affect colonization of the plants by B. bassiana.

The endophytic colonization of sorghum by B. bassiana suggests that this isolate is well adapted to a wide range of conditions including endophytic in plants and pathogenic to insects. B. bassiana can become established as an endophyte in sorghum without adversely affecting plant growth, and leaf inoculation with a conidial suspension proved to be the best method to introduce $B$. bassiana into sorghum leaves. This study provides the basis for further investigations, which should focus on the response of different sorghum cultivars to different strains of B. bassiana, the long term establishment throughout the entire life of the inoculated plants, and the virulence of the endophytic $B$. bassiana against sorghum stem borers. An application technology should be developed that protects $B$. bassiana conidia against soil antagonism in order to maximize endophytic colonization by the fungus in non-sterile soil.

Acknowledgments This study was funded by the Alexander von Humboldt Foundation, Bonn. We appreciate the comments of two anonymous reviewers.

Open Access This article is distributed under the terms of the Creative Commons Attribution Noncommercial License which permits any noncommercial use, distribution, and reproduction in any medium, provided the original author(s) and source are credited.

\section{References}

Akello J, Dubois T, Gold CS, Coyne D, Nakavuma J, Paparu P (2007) Beauveria bassiana (Balsamo) Vuillemin as an endophyte in tissue culture banana (Musa spp.). J Invertebr Pathol 96:34-42

Bills GF, Polishook JD (1991) Microfungi from Carpinus caroliniana. Can J Bot 69:1477-1482

Bing LA, Lewis LC (1991) Suppression of Ostrinia nubilalis (Hubner) (Lepidoptera: Pyralidae) by endophytic Beauveria bassiana (Balsamo) Vuillemin. Environ Entomol 20:1207-1211

Bing LA, Lewis LC (1992a) Temporal relationships between Zea mays, Ostrinia nubilalis (Lepidoptera: Pyralidae) and endophytic Beauveria bassiana. Entomophaga 37:525-536 
Bing LA, Lewis LC (1992b) Endophytic Beauveria bassiana (Balsamo) Vuillemin in corn: the influence of plant growth stages and Ostrinia nubilalis (Lepidoptera: Pyralidae). Biocon Sci Technol 2:39-47

Bosque-Perez NA, Schulthess F (1998) Maize in west and central Africa. In: Polaszek A (ed) African cereal stem borers. Economic importance, taxonomy, natural enemies and control. CAB International, Wallingford, pp 11-24

Chase AR, Osborne LS, Ferguson VM (1986) Selective isolation of the entomopathogenic fungi Beauveria bassiana and Metarhizium anisopliae from an artificial potting medium. Fla Entomol 69:285-292

Evans HC, Holmes KA, Thomas SE (2003) Endophytes and mycoparasites associated with an indigenous forest trees, Theobroma gileri, in Ecuador and a preliminary assessment of their potential as biocontrol agents of cocoa diseases. Mycol Prog 2:149-160

Ganley RJ, Newcombe G (2005) Fungal endophytes in seeds and needles of Pinus monticola. Mycol Res 110:318-327

Goettel MS, Inglis GD (1997) Fungi: Hyphomyctes. In: Lacey LA (ed) Manual of techniques in insect pathology. Academic Press, San Diego, pp 212-249

Jallow MFA, Dugassa-Gobena D, Vidal S (2004) Indirect interaction between an unspecialized endophytic fungus and a polyphagous moth. Basic Appl Ecol 5:183-191

Jallow MFA, Dugassa-Gobena D, Vidal S (2008) Influence of an endophytic fungus on host plant selection by a polyphagous moth via volatile spectrum changes. Arthropod-Plant Interact 2:53-62

Jones KD (1994) Aspects of the biology and biological control of the European corn borer in North Carolina. Ph.D. thesis, Department of Entomology, North Carolina State University

Kessler P, Matzke H, Keller S (2003) The effect of application time and soil factors on the occurrence of Beauveria brongniartii applied as a biological control agent in soil. J Invertebr Pathol 84:15-23

Lewis LC, Bruck DJ, Gunnarson RD, Bidne KG (2001) Assessment of plant pathogenicity of endophytic Beauveria bassiana in Bt transgenic and non-transgenic corn. Crop Sci 41:1395-1400

Liang-Dong G, Guo-Rui H, Yu W (2008) Seasonal and tissue age influences on endophytic fungi of Pinus tabulaeformis (Pinaceae) in the Dongling Mountains, Beijing. J Integr Biol 50:997-1003

Lingg AJ, Donaldson MD (1981) Biotic and abiotic factors affecting stability of Beauveria bassiana conidia in soil. J Invertebr Pathol 38:191-200

Majchrowicz I, Poprawski T, Maniania NK, Robert PH (1990) Effects of entomopathogenic and opportunist fungi on
Delia antiqua (Diptera: Anthomyiidae) at low relative humidity. Environ Entomol 19:1163-1167

Ownley BH, Griffin MR, Klingeman WE, Gwinn KD, Moulton JK, Pereira RM (2008) Endophytic colonization and plant disease control. J Invertebr Pathol 98:267-270

Pereira RM, Stimac JL, Alves SB (1993) Soil antagonism affecting the dose-response of workers of the red imported fire ant, Solenopsis invicta, to Beauveria bassiana conidia. J Invertebr Pathol 61:156-161

Petrini O, Fisher PJ (1987) Fungal endophytes in Salicornia perennis. Trans British Mycol Soc 87:647-651

Posada F, Vega FE (2005) Establishment of the fungal entomopathogen Beauveria bassiana (Ascomycota: Hypocreales) as an endophyte in cocoa seedlings (Theobroma cacao). Mycologia 97:1195-1200

Posada F, Vega FE (2006) Inoculation and colonization of coffee seedling (Coffea arabica L.) with the fungal entomopathogen Beauveria bassiana (Ascomycota: Hypocreales). Mycoscience 47:284-289

Posada F, Aime MC, Peterson SW, Rehner SA, Vega FE (2007) Inoculation of coffee plants with the fungal entomopathogen Beauveria bassiana (Ascomycota: Hypocreales). Mycol Res 111:748-757

Quesada-Moraga E, Landa BB, Munoz-Ledesma J, JimenezDiaz RM, Santiago-Alvarez C (2006) Endophytic colonization of opium poppy Papaver somniferum by an entomopathogenic Beauveria bassiana strain. Mycopathol 161:323-329

Shields MS, Lingg AJ, Heimsch RC (1981) Identification of a Pencillium urticae metabolite which inhibits Beauveria bassiana. J Invertebr Pathol 38:374-377

Tefera T, Pringle K (2004) Evaluation of Beauveria bassiana and Metarhizium anisopliae, for controlling Chilo partellus (Lep.: Crambidae) in maize. Biocon Sci Technol 14:849-953

Van Rensburg JBJ, Van Den Berg J (1992) Infestation patterns of stalk borers Busseola fusca Fuller (Lep.: Noctuidae) and Chilo partellus Swinhoe (Lep.: Pyralidae) in sorghum. J Entomol Soc South Afr 55:197-212

Vänninen I, Tyni-Juslin J, Hokkanen H (2000) Persistence of augmented Metarhizium anisopliae and Beauveria bassiana in Finnish agricultural soils. BioControl 45: 201-222

Wagner BL, Lewis LC (2000) Colonization of corn, Zea mays, by the entomopathogenic fungus Beauveria bassiana. Appl Environ Microbiol 66:3468-3473

Warui CM, Kuria JN (1983) Population incidence and control of maize stalk borers Chilo partellus, C. orichalcociliellus and Sesamia calamistis in Coast Province, Kenya. Insect Sci Appl 4:11-18 